\title{
MONITORING POWER PLANT EFFICIENCY USING THE MICROWAVE-EXCITED PHOTOACOUSTIC EFFECT TO MEASURE UNBURNED CARBON
}

\author{
Quarterly Technical Progress Report
}

Reporting Period Start Date: April 1, 2002

Reporting Period End Date: June 30, 2002

Principal Author(s):

Robert C. Brown, Robert J. Weber, and Andrew A. Suby

Date Report Issued:

July 2002

DOE Award Number:

DE-FC22-01NT41220

Submitted By:

Center for Sustainable Environmental Technologies

Iowa State University

285 Metals Development Bldg.

Ames, IA 50011-3020 


\section{DISCLAIMER}

This report was prepared as an account of work sponsored by an agency of the United States Government. Neither the United States Government nor any agency thereof, nor any of their employees, makes any warranty, express of implied, or assumes any legal liability or responsibility for the accuracy, completeness, or usefulness of any information, apparatus, product, or process disclosed, or represents that its use would not infringe privately owned rights. Reference herein to any specific commercial product, process, or service by trade name, trademark, manufacturer, or otherwise does not necessarily constitute or imply its endorsement, recommendation, or favoring by the United States Government or any agency thereof. The views and opinions of authors expressed herein do not necessarily state or reflect those of the United States Government or any agency thereof. 


\section{ABSTRACT}

Three test instruments are being evaluated to determine the feasibility of using photoacoustic technology for measuring unburned carbon in fly ash. The first test instrument is a single microwave frequency system previously constructed to measure photo-acoustic signals in an off-line configuration. This system was assembled and used to test parameters thought important to photo-acoustic signal output. A standard modulation frequency was chosen based upon signal to noise data gained from experimentation. Sample heterogeneity was tested and found not to be influential. Further testing showed that sample compression and photo-acoustic volume do affect photo-acoustic signal. Many tests were performed in the third quarter, which included the effects of ambient temperature and humidity, as well as sample moisture content, and signal linearity. Conclusions regarding the data for sample bulk density and temperature are pending further review and may require further testing.

Simultaneously, a second instrument is being constructed based in part on lessons learned with the first instrument, but which also expands the capabilities of the first instrument. Improvements include a control loop to allow more constant microwave power output and an ability to operate over a range of microwave frequencies. To date, all of the components for the second instrument have been received and most of them tested with the exception of the broadband impedance transformers, as they will be incorporated into the second instrument test chamber. The third instrument will be designed based on the experiences of the first two instruments and will operate in an on-line carbon-in-ash monitoring system for coal-fired power plants.

Keywords: fly ash, carbon monitor, unburned carbon, boiler instrumentation 


\section{TABLE OF CONTENTS}

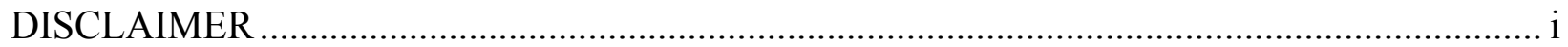

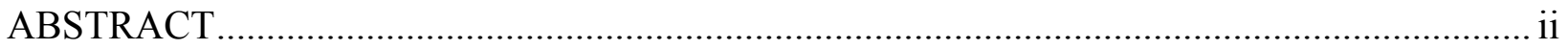

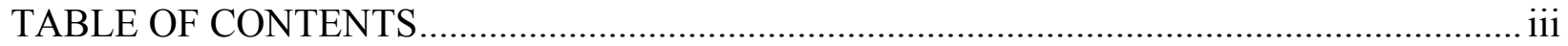

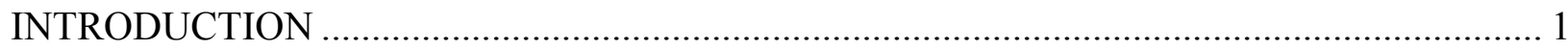

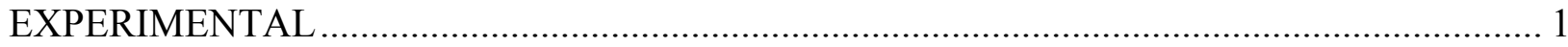

The Single Microwave Frequency, Off-Line Instrument .......................................... 1

The Microwave Spectrometer......................................................................... 2

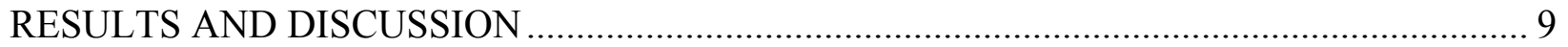

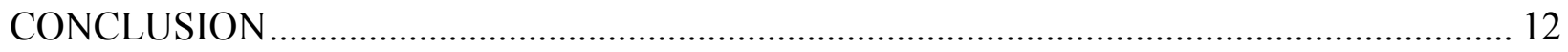

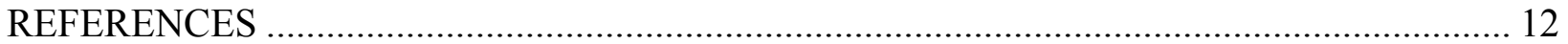

APPENDIX A 


\section{INTRODUCTION}

The objective of this project is to explore the use of the microwave-excited photoacoustic (MEPA) effect for quantitative analysis of granular and powdered materials. The focal point of the research centers on the measurement of unburned carbon in fly ash, an important parameter in the electric utility industry used to determine plant efficiencies. The culmination of this project will be an on-line carbon-in-ash monitor for coal-fired power plants. However, evaluations will be made on other powdered solids, particularly coal.

The approach to this project includes work with three MEPA instruments. The first instrument is a single microwave frequency, off-line instrument built at Iowa State University as part of proof-of-concept evaluations. It is being used to evaluate precision and accuracy of the MEPA technique. The second instrument is being constructed as a microwave spectrometer based on MEPA. It will be used to evaluate a variety of industrial important powders, including fly ash and pulverized coal. The final instrument will be built based on the results of work with the previous two instruments and will be used as an on-line monitor of unburned carbon in fly ash.

\section{EXPERIMENTAL}

\section{The Single Microwave Frequency, Off-Line Instrument}

Testing was continued to determine parameters that affect photo-acoustic measurement accuracy and precision. Variables examined (to date) which may influence the photo-acoustic signal include: sample heterogeneity, sample bulk density, sample compression, sample moisture content, modulation frequency, signal to noise ratio, and photoacoustic volume. Ambient temperature and humidity were also examined. 
Testing continued with fly ash samples obtained from Duquesne/Elrama boiler 3B located in Pennsylvania, as well as other fly ash used in previous experiments and some carbon black/dolomite mixtures. Upon review of test procedures and data taken last quarter, tests were repeated for sample moisture content, compression, and ambient temperature and humidity to determine repeatability of the instrument. Several tests were also run to determine the linearity of the $\%$ carbon signal. Test parameters for a representative linearity test using the Duquesne/Elrama fly ash are outlined in Appendix A.

\section{The Microwave Spectrometer}

The task for design and construction for the microwave portion of an improved MEPA Spectrometer for the first year is given below. The progress on this task during the third quarter was consistent with task milestones. As will be discussed in the paragraphs below, there was some revision in the design of the microwave system of the spectrometer based on experiments carried out in the third quarter.

\section{Task 2. Design and construct an improved MEPA spectrometer.}

2.1 Purchase equipment.

2.1.1 Purchase broadband microwave generator. End of month 3

2.1.2 Purchase microwave amplifier. End of month 3

2.1.3 Purchase broadband impedance transformers. End of month 9

2.1.4 Purchase miscellaneous equipment. End of month 6

2.2 Design off-line MEPA spectrometer based on results from Task 1 with operating range from $0.5-10 \mathrm{GHz} . \quad$ End of month 6

2.3 Construct off-line MEPA spectrometer with operating range of $0.5-10 \mathrm{GHz}$ Months 7-11

2.4 Demonstrate operability of MEPA spectrometer. milestone

The microwave work for the MEPA project during the third quarter focused on subtasks 2.1.4 and 2.2 as well as performing part of subtask 2.3. All the equipment and materials purchased during the second quarter of the project were tested during the third quarter except the 4 - $10 \mathrm{GHz}$ power amplifier. 
Instead of purchasing the broadband impedance transformers, described in subtask 2.1.3, it was decided to integrate them with a new test chamber that will be fabricated during the next two quarters. The design of the transformers was completed during the third quarter. A three section or a four section Dolph-Chebyshev quarter wavelength section will be used to transform to $25 \mathrm{ohms}$ and to $100 \mathrm{ohms}$ from $50 \mathrm{ohms}$. The low and high impedance test cells will be designed to operate from nominally $1 \mathrm{GHz}$ to $4 \mathrm{GHz}$. The overall spectrometer will operate from 0.5 to $10 \mathrm{GHz}$; however, the low and high impedance testing will be done in the nominally 1 to $4 \mathrm{GHz}$ region. Different transformers will be fabricated should testing indicate that other frequencies be considered for alternate impedance testing.

Since the microwave power source and the microwave detector are each $50 \mathrm{ohm}$ systems, two transformer sections are needed as shown in Figure 1. The impedance of the stripline assembly for a low impedance test is changed from $50 \mathrm{ohms}$ to $25 \mathrm{ohms}$ with the impedance matching section. The impedance is changed back from 25 ohms to 50 ohms with another impedance matching section.

Figure 1. Transformer sections.

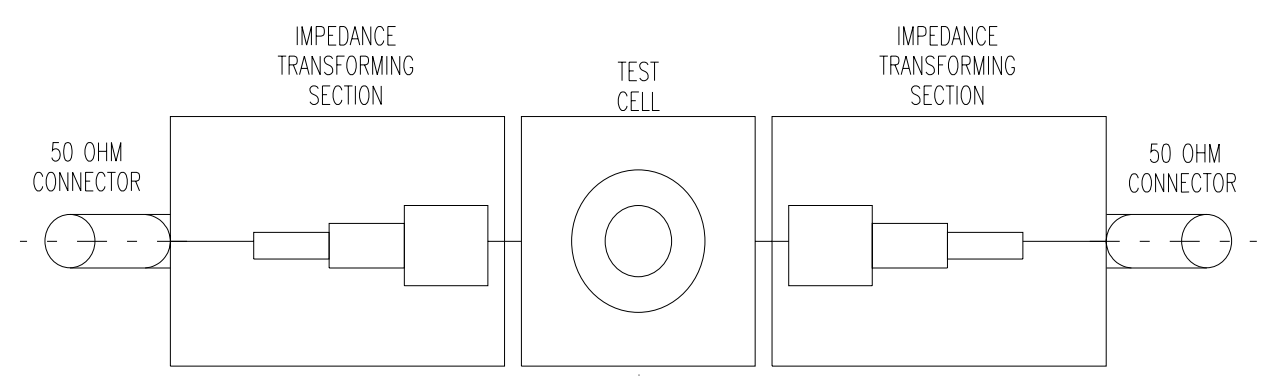

In order to provide for a very low voltage standing wave ratio (VSWR) in the test cell, these impedance matching sections need to be designed with better than $30 \mathrm{~dB}$ return loss. A 30 $\mathrm{dB}$ return loss is equivalent to a 1.065:1 VSWR. The power reflected in a $50 \mathrm{ohm}$ system would only be $0.1 \%$. However, cascaded sections with a $30 \mathrm{~dB}$ return loss can give a voltage variation 
as high as $6 \%$. Since the photo-acoustic effect is related to the square of the voltage on the line, a variation of voltage in the photo-acoustic of $6 \%$ voltage would give a photo-acoustic signal variation as high as $12 \%$. A $20 \mathrm{~dB}$ return loss would give as much as a $36 \%$ variation in the photo-acoustic signal. Using only four quarter-wavelength sections in a Dolph-Chebyshev design for the matching sections, a low VSWR (approximately $30 \mathrm{~dB}$ return loss) can be provided over almost a four to 1 (4:1) frequency range. Figure 2 shows that a two-section match will work over approximately a 2:1 frequency range and a four-section match will work over a 4:1 frequency range. The four-section match shown is centered from 0.8-3.15 GHz. Changing the matching sections from quarter wavelengths at $2 \mathrm{GHz}$ to $2.5 \mathrm{GHz}$ will allow the transformers to work from 1 to $4 \mathrm{GHz}$.

The characteristic impedances for the two-step transformer for $707-1414 \mathrm{MHz}$ are:

$Z(0)=25.000$ load

$Z(1)=30.475$

$Z(2)=41.017$

$Z(3)=50.000$ source

and the four step transformer for $1-4 \mathrm{GHz}$ are:

$Z(0)=25.000$ load

$Z(1)=27.867$

$Z(2)=32.378$

$Z(3)=38.607$

$Z(4)=44.856$

$Z(5)=50.000$ source 
Figure 2. Return loss vs. frequency for 2-, 3-, and 4section Dolph-Chebyshev quarter wavelength sections.
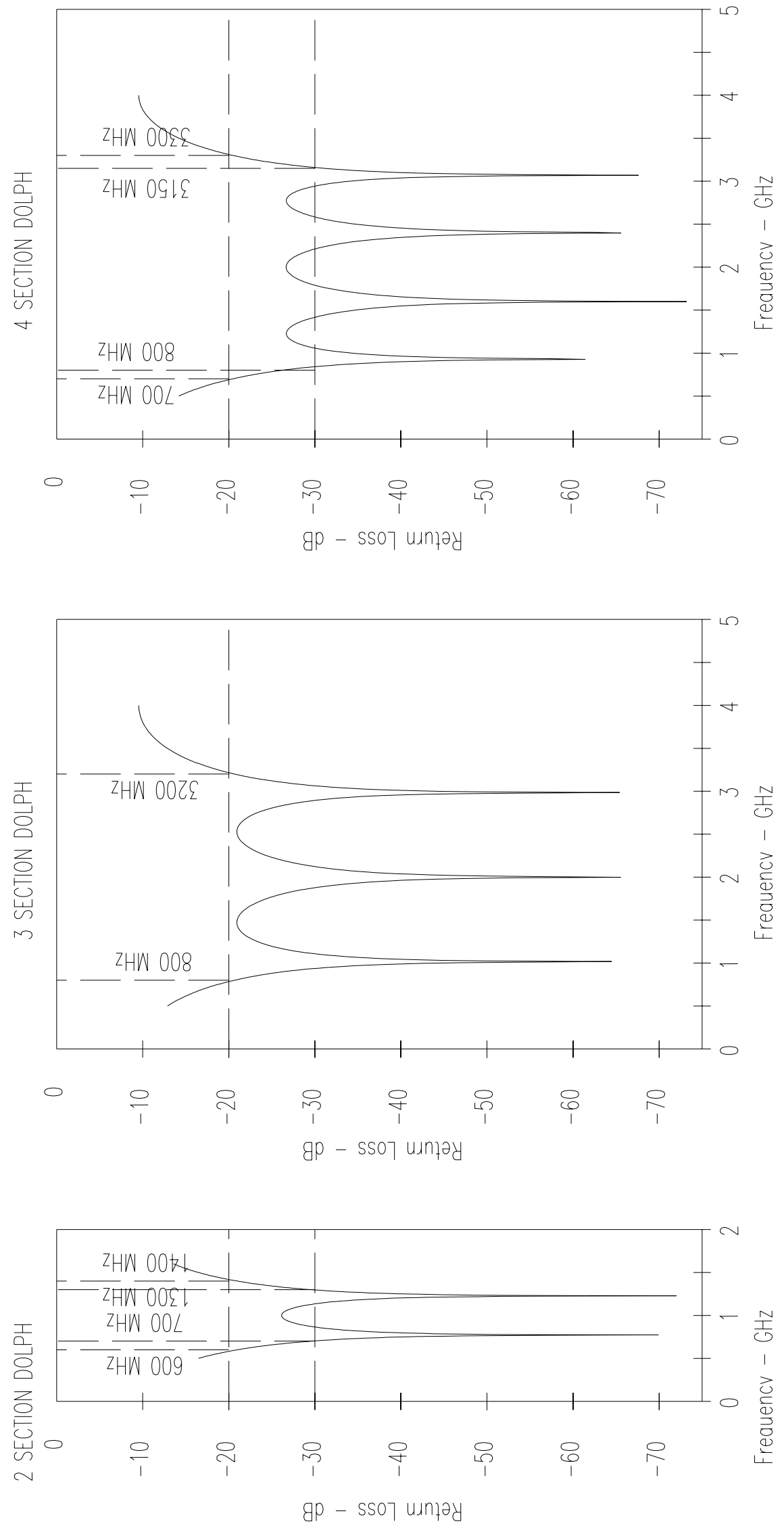
The initial circuit used for power level control is shown in Figure 3. A significant amount of time was spent with this circuit. Two difficulties were apparent with the circuit. The first was that the modulation characteristics of the mixer did not have sufficient dynamic range, i.e., on/off ratio. The second was that the mixer circuit did not have a positive slope (attenuation versus voltage) for all attenuation levels. This presented some difficulty in the control loop.

Figure 3. Initial power level control circuit.

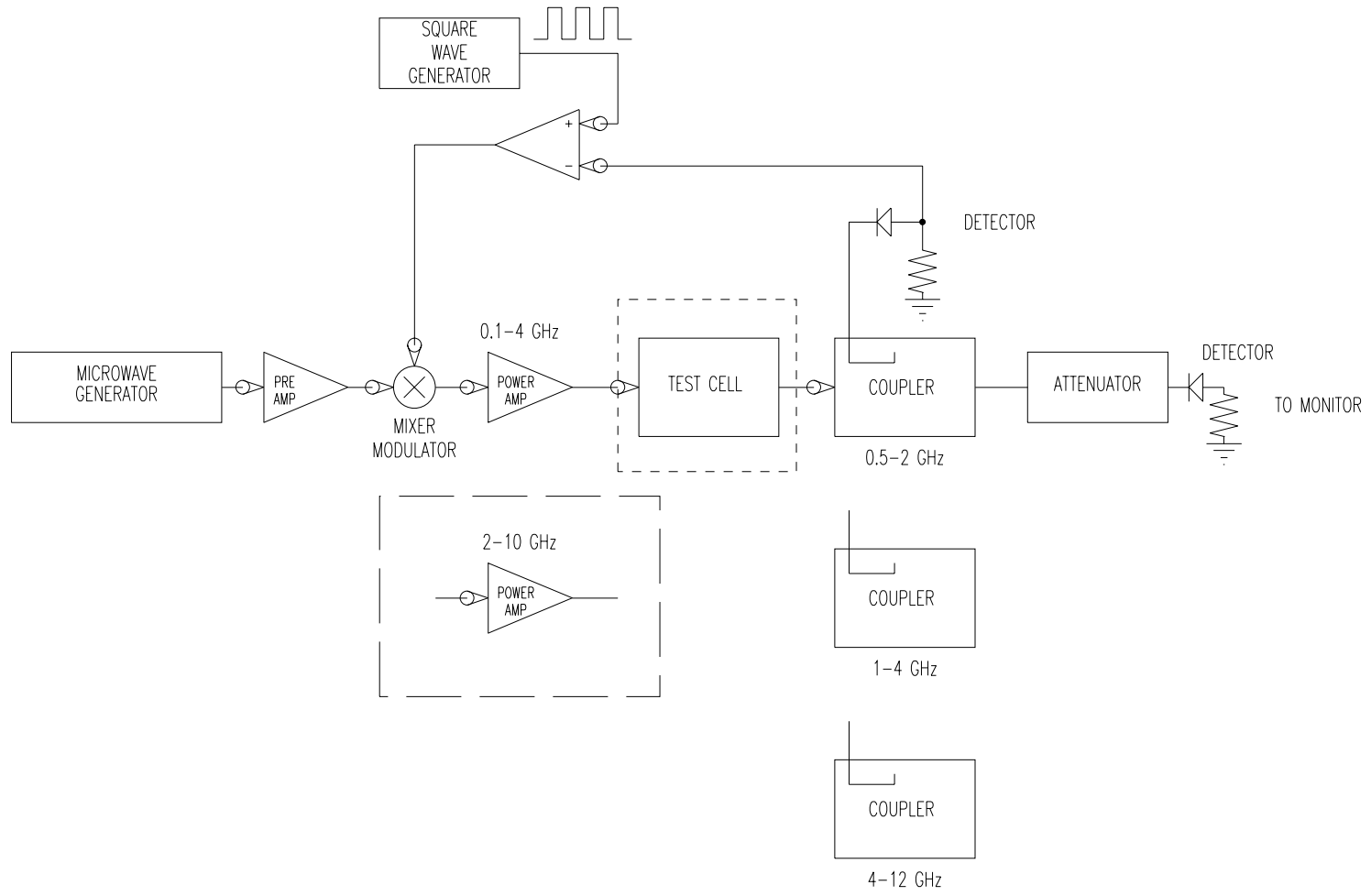

The mixer was replaced with a collector modulated small signal amplifier stage and a switch. This is shown in Figure 4. However, the filter shown with a double arrow to the left side of the next figure was not initially added. This circuit had sufficient on/off ratio and modulation characteristics but still showed a significant amount of power variation. It was determined that the collector modulated small signal amplifier was generating harmonic power as well as fundamental power. Since the detector on the loop works on voltage peaks, the amount of power "detected" was influenced by the harmonic power. 
Figure 4. Updated power level control circuit.

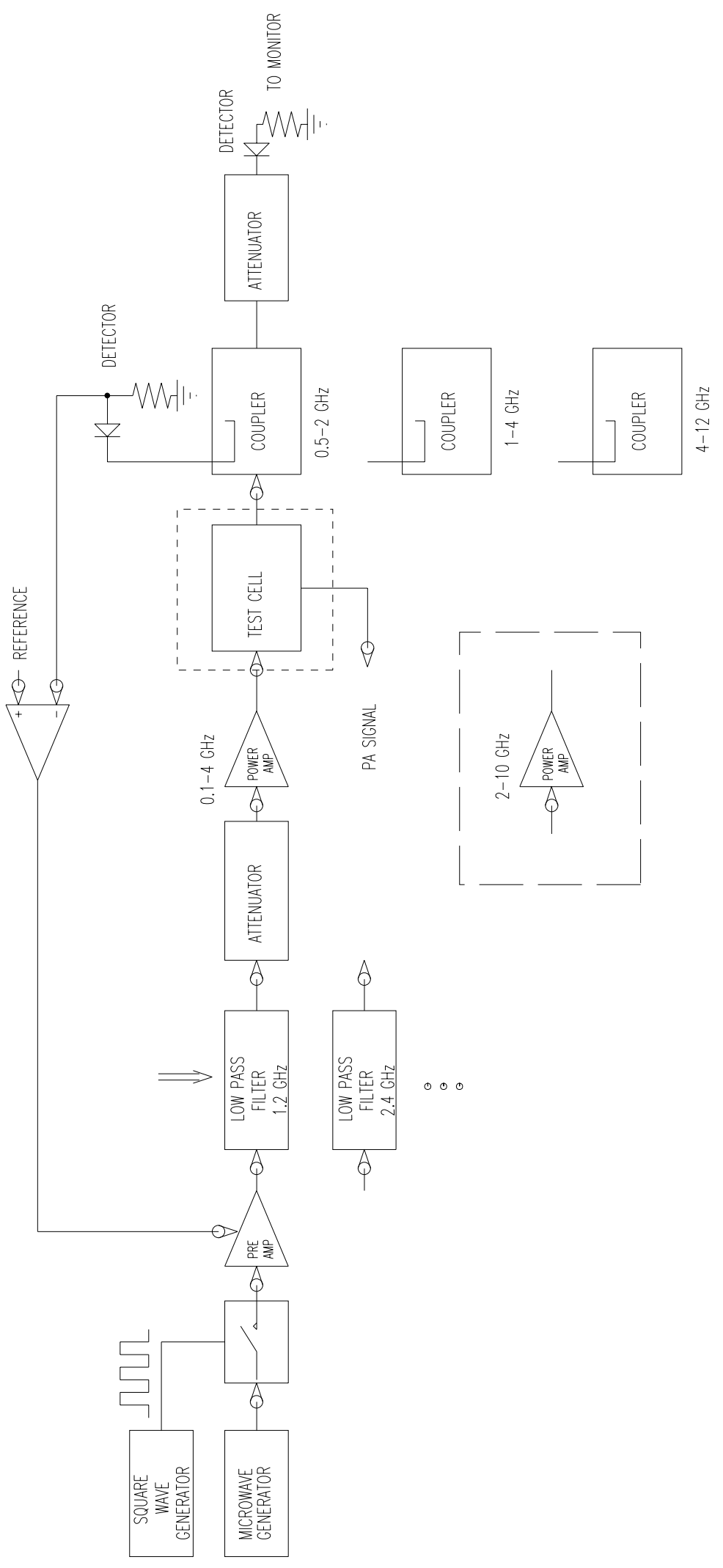


Only one percent harmonic energy gives ten percent voltage variation. The effective power can be off by 1.21 or .81 or over a $20 \%$ power variation. A 10 pole, low pass filter was inserted between the small signal amplifier and the power amplifier, when it was determined that the small signal amplifier was generating harmonic power.

Second harmonic power will require that a separate filter be designed for every octave of bandwidth required. Examples would include: $0.5-1 \mathrm{GHz}, 1-2 \mathrm{GHz}, 2-4 \mathrm{GHz}, 4-8$, GHz etc. A 1.2 $\mathrm{GHz}$ ten pole, low pass filter was fabricated, inserted, and tested with the system. The system then produced the same output power for over $10 \mathrm{~dB}$ input power variation.

This control loop will remedy the difficulty that was experienced in long time duration tests in the pre-proposal tests. When the power amplifier is used for a considerable amount of time, it heats up and its power output droops. The control loop will be used to set the power output of the power amplifier at a level just less than its maximum amount of power generation capability when it is hot. Then, when the amplifier is operating at turn on, the control loop will limit the input power available to the amplifier and thus the output power generated. The output power will be kept substantially constant for the operating temperatures of the power amplifier.

A ten-pole, $1.2 \mathrm{GHz}$, low pass filter has a passband as shown in Figure 5. The insertion loss at the second harmonic attenuation is greater than $20 \mathrm{~dB}$ for signals from $750 \mathrm{MHz}$ to 1 GHz. 
Figure 5. 10-pole, $1.2 \mathrm{GHz}$, low-pass filter passband.

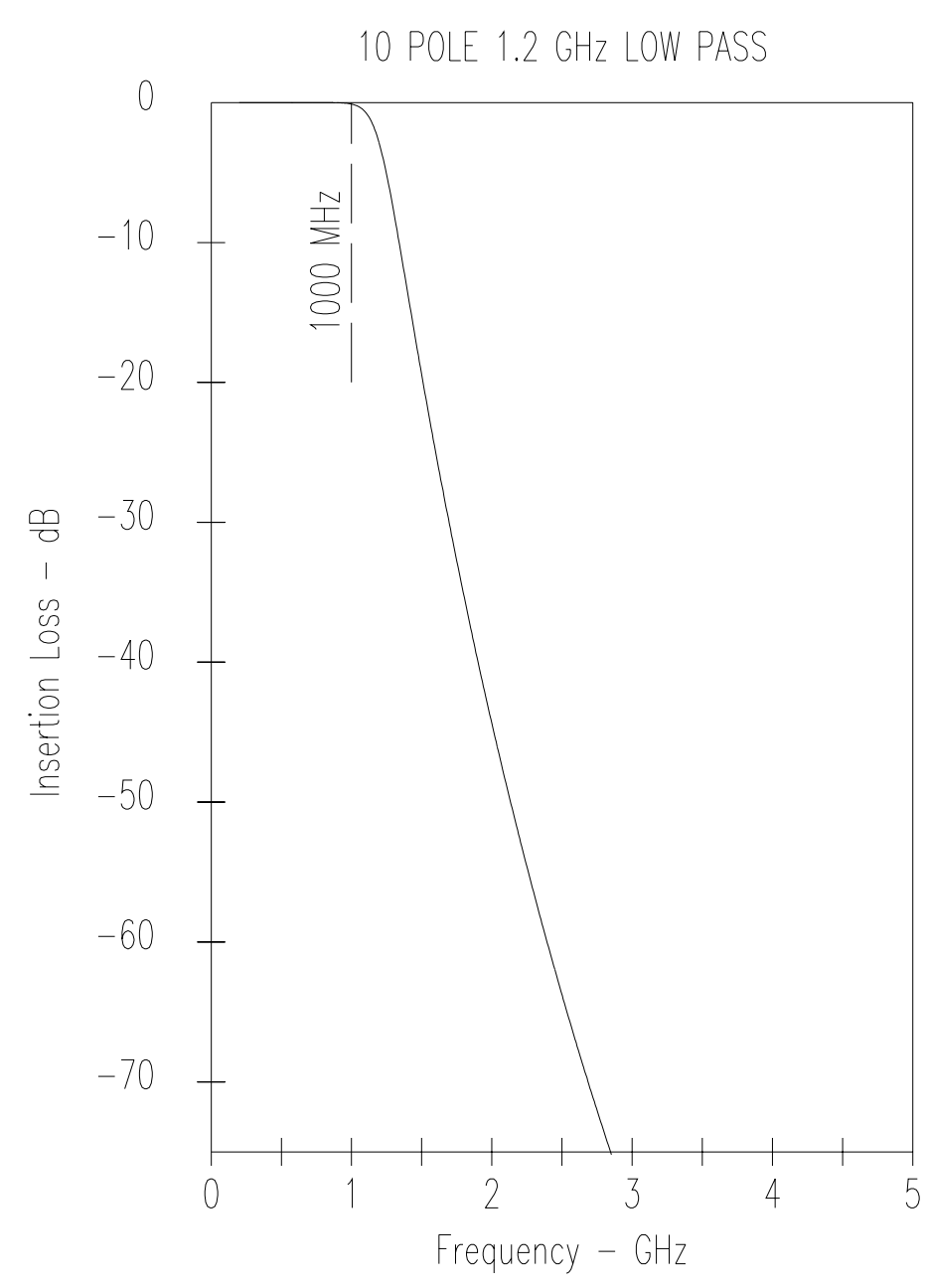

\section{RESULTS AND DISCUSSION}

The results for the linearity test are shown in Figure 6. The data set shows poor linearity due to the signals recorded for the fly ash reported to contain $14.49 \%$ carbon as determined by the Unburned Carbon methodology ${ }^{1}$. Since photoacoustic theory suggests that under these conditions photoacoustic signal should be proportional and linear to the concentration of the absorbing material (carbon), this result was unexpected. The test was repeated and similar results were obtained. 
Figure 6. Signal Measured for Various 3B Boiler Flyashes vs. \% Carbon Using the Unburned Carbon (UC) Methodology (Test XVI: Linearity) 2/7/02

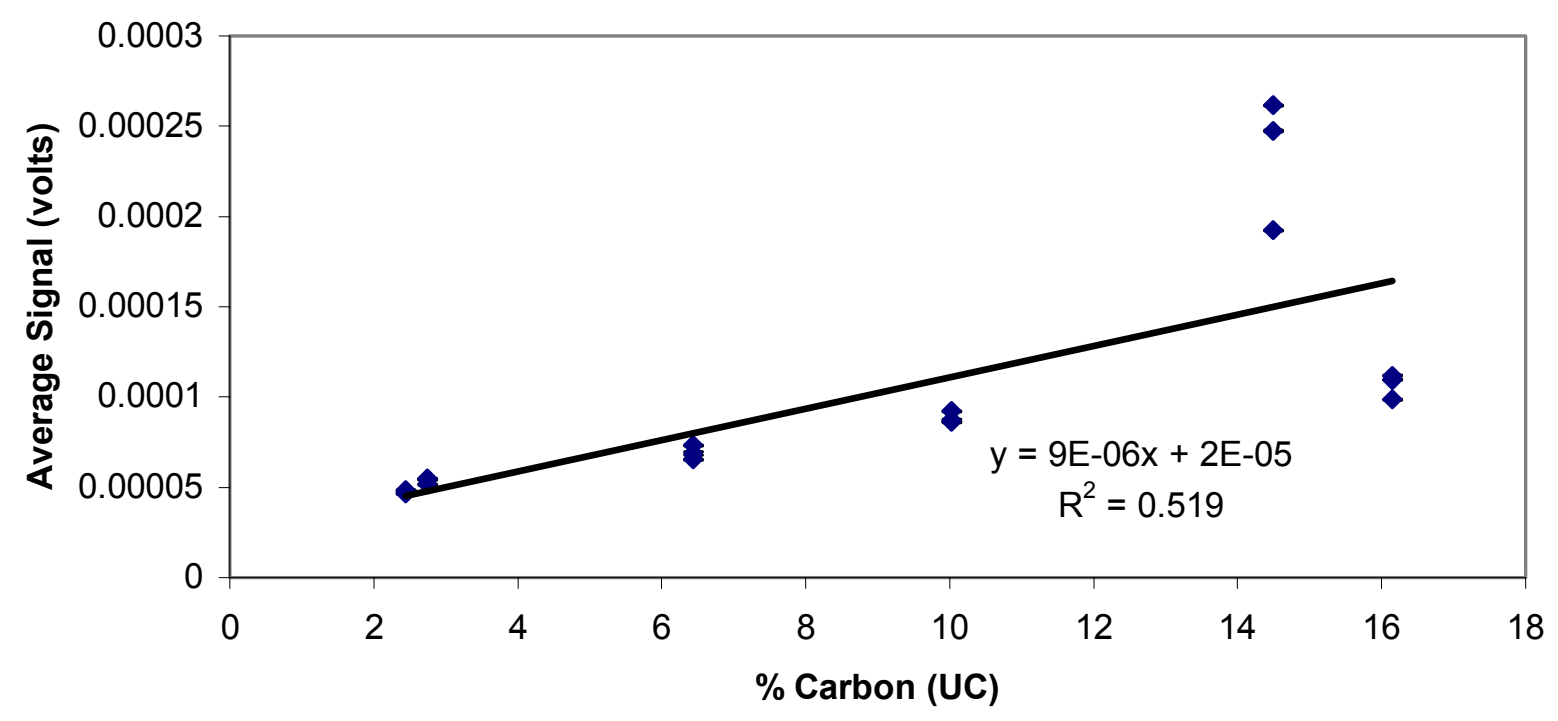

Further testing was done with carbon black and dolomite mixtures, as well as with fly ash obtained from pulverized coal and stoker type combustors. These results are shown in Figures 7 and 8 respectively. Both show improved linearity. The data shown in Figure 8 is similar to results obtained from earlier testing under similar conditions in $1998^{2}$. 
Figure 7. Signal Measured for \% Carbon Black (Test XVIC: Linearity, Dried, Similarity) 5/30/02

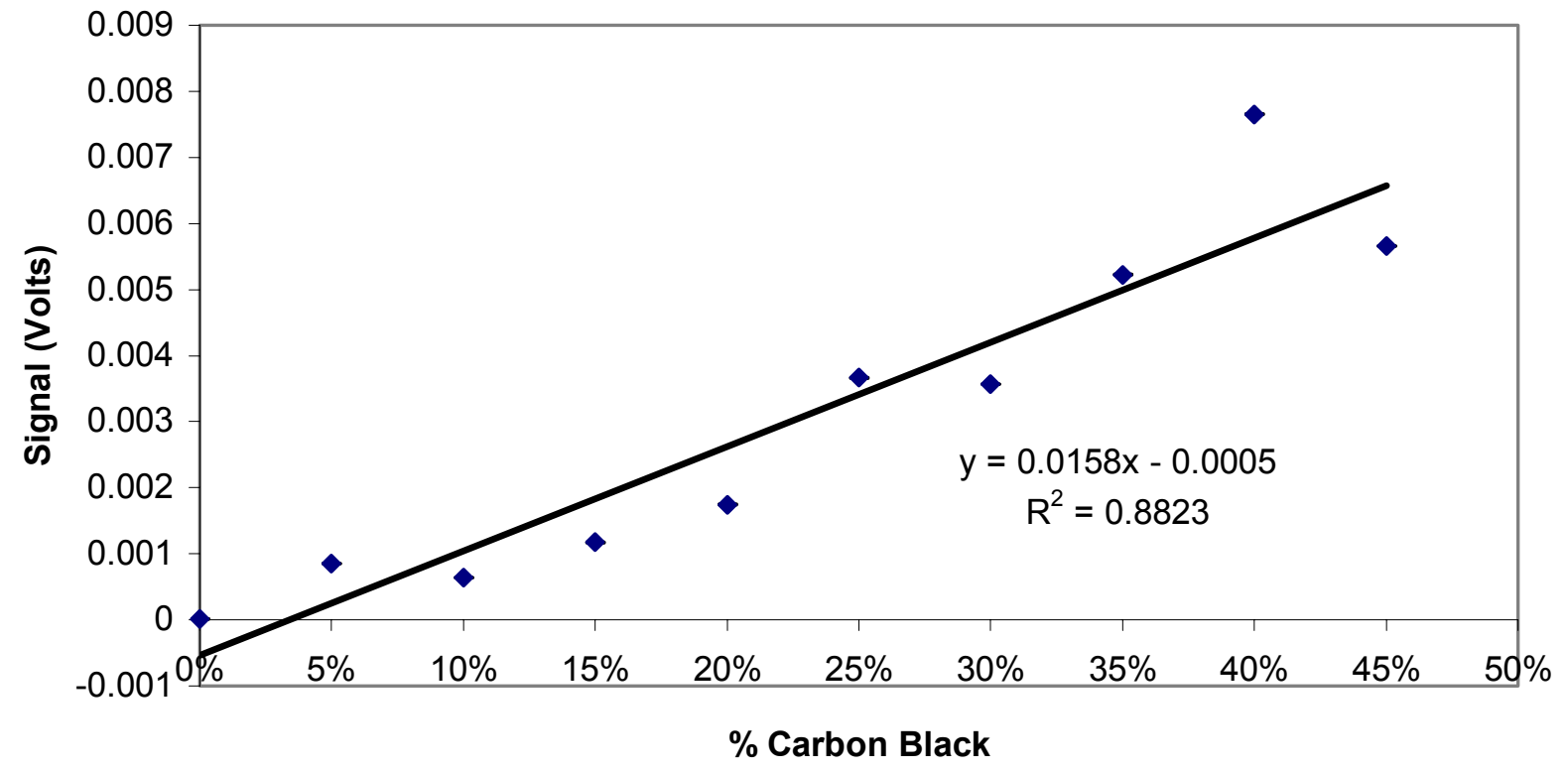

Figure 8. Signal Measured for Various Waller Flyashes vs. \% Carbon Using the Total Organic Carbon (TOC) Methodology (Test XVIB: Linearity, Dried) $3 / 12 / 02$

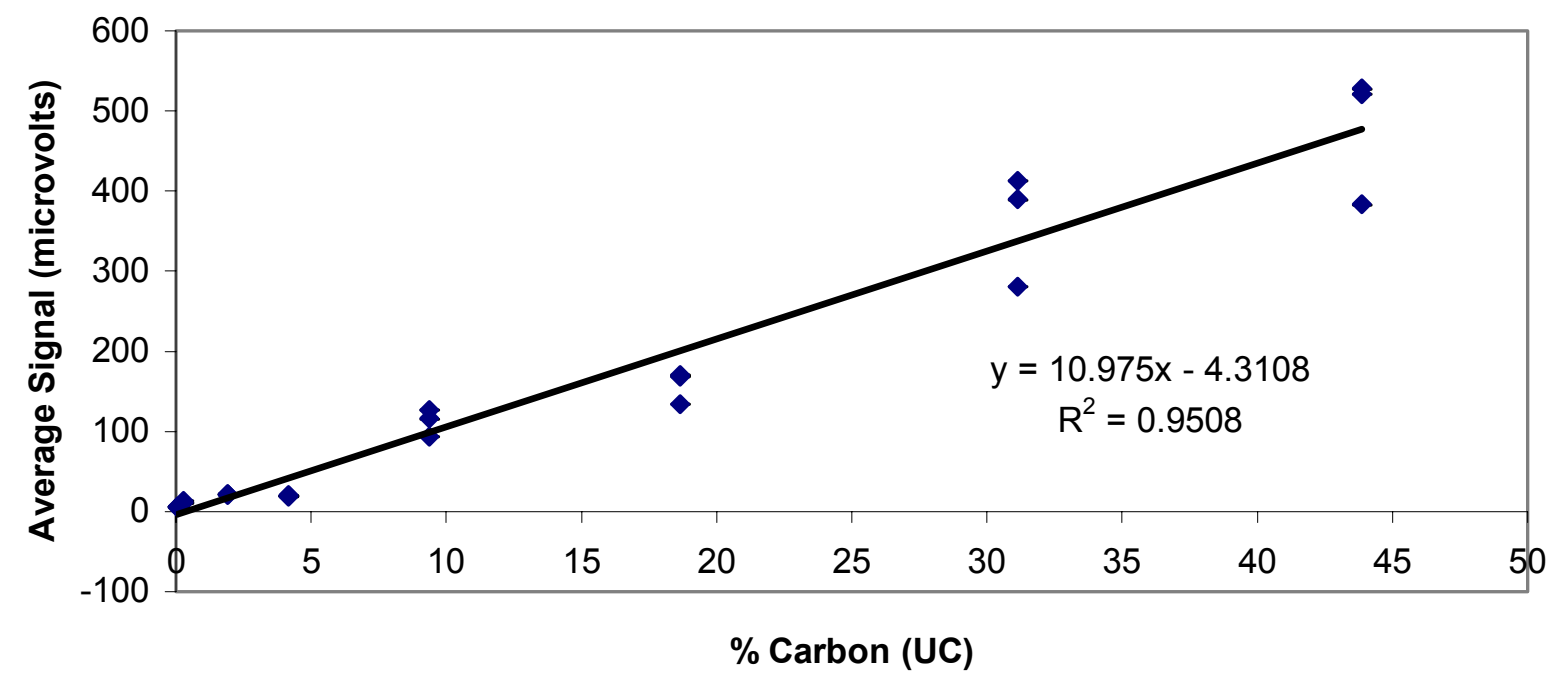




\section{CONCLUSION}

The Duquesne/Elrama boiler 3B fly ash samples need further review to determine if the reported carbon concentrations are correct or whether there are other possible absorbing materials (such as potentially iron oxides) causing non-linear measurements to be obtained. Examination of other fly ash samples as well as carbon black and dolomite mixtures show better linearity as predicted by theory. Sample moisture content tests have been conducted and show that a better way of hydrating the fly ash sample is in order as only $1 \%$ moisture by mass was obtained in during the hydration process. Past testing has shown an influence on signal and further testing should confirm this. Initial indications show that ambient temperature and humidity effects are negligible, which would confirm previous testing performed in $1998^{2}$. Sample bulk density, temperature, and the effects of grinding tests are pending.

Essentially all of the milestones for the MEPA spectrometer are accomplished through the third quarter. The purchase of broadband transformers has been replaced with the DolphChebyshev transformer design. These transformers will be fabricated in the fourth quarter.

\section{REFERENCES}

${ }^{1}$ Brown, R.C. Private Communication, Iowa State University, Ames, 2000.

2 Suby, Andrew A., "Detection of carbon using microwave excited photoacoustic spectroscopy." Master's Thesis, Iowa State University, Ames, 1998. 


\title{
APPENDIX A SYSTEM TEST SETUP
}

\author{
GENERAL INFORMATION $\quad$ VERSION: 1.0 \\ Principle Investigator: Brown (Suby), Weber \\ Test Group: NETL (DOE) \\ Test Name: TestXVI \\ Expected duration of test: $\underline{3 \text { hours }}$ \\ Date: $1 / 31 / 02$ \\ Phone: (515) 382-9006 \\ E-mail: asuby@iastate.edu \\ Program: Lock-in2.bas, PAS.xls \\ Data: $\$ Public $\square$ Private \\ Description of test: Linearity. \\ -Select 6 fly ashes of different carbon content from the 3B boiler. \\ ${ }^{* * *}$ Perform the following procedures 3 times for each flyash: \\ -Weigh and record the weight of the empty sample holder. \\ -Fill the sample holder with sample and compress the sample as described in the produres entitled "Filling \\ the Sample Holder" (SampleSOP.doc) and "Compressing a Fly ash Sample" (CompSampSOP.doc). \\ -Measure and record PA volume (depth) and weigh and record the holder and sample. \\ -Measure PA signal, and dump sample back into original sample bottle. \\ -Clean sample holder throughly with compressed air.
}

Objective of test: $\underline{\text { To assemble a PA signal vs. carbon curve and determine linearity }}$

Variables under consideration: Carbon Content

Variables to be held constant: PA Volume, Sample Temp and Humidity (assumed), Ambient Temp and Humidity (assumed), Modulation Frequency

\section{SPECIAL REQUIREMENTS}

\begin{tabular}{|c|c|}
\hline SYSTEM SETUP & DAtA COLLECTEd By: NL \\
\hline $\begin{array}{l}\text { SAMPLE INFORMATION: } \\
\text { Sample Designation: See Notes: }\end{array}$ & $\begin{array}{l}\text { Deliverables: } \\
\text { 1) Plot PA signal vs carbon content }\end{array}$ \\
\hline $\begin{array}{l}\text { Sample Preparation: } \\
\square \text { "As Received" (no preparation) } \\
\square \text { Compressed } \\
\square \text { Ground } \\
\square \text { Dried } \\
\text { Notes: } \\
\text { Recommend the following fly ash: } 21960 A T \text {, } \\
\text { 22332AT, 22339AT, 22342AT, 22360AT, and } \\
\text { 22368AT }\end{array}$ & $\begin{array}{l}\text { SYSTEM INFORMATION: } \\
\text { Modulation Frequency: } 20 \\
\text { Raw Data File Naming Convention: } \\
\text { 1) Refer to the Document Entitled "Raw Data File } \\
\text { Naming Convention for the Lock-in Data } \\
\text { Acquisition System" (DOSDataCon.doc) } \\
\text { Notes: } \\
\text { 1) Refer to the system Standard Operating } \\
\text { Procedures (SystemSOP.doc) }\end{array}$ \\
\hline
\end{tabular}

